Pre-proof version. Manuscript accepted for publication in Applied Linguistics.

\title{
Event-frames affect blame assignment and perception of aggression in discourse on political protests: An experimental case study in critical discourse analysis
}

Christopher Hart (Lancaster University)

c.hart@lancaster.ac.uk

\begin{abstract}
While CDA is largely an interpretative exercise, it places an emphasis on 'triangulation' as a guiding methodological principle intended to help ground analyses and guard against purely subjective readings of texts. Missing from CDA, however, is triangulation incorporating experimental methodologies. In this paper, I argue that CDA in general can benefit from an experimental dimension and that Cognitive Linguistic approaches in particular lend themselves to extension into experimentalism. I demonstrate this by reporting a recent experiment carried out within a Cognitive Linguistic framework on the effects of regular transactive versus reciprocal verbs in news reports of political protests. Results of the experiment show that in the context of media discourse on political protests the presentation of these alternate constructions, as well as differences in information sequence, affect how people apportion blame and the level of aggression they perceive in social actors. The experiment thus not only provides evidence for the ideological effects of these particular linguistic differences but more generally goes some way to justifying CDA's focus on micro-level lexico-grammatical features of texts.
\end{abstract}

Key words: critical discourse analysis, triangulation, experimentation, political protests, eventframes, regular transactive verbs, reciprocal verbs

\section{Introduction}

Critical Discourse Analysis (CDA) is an inherently interdisciplinary approach to discourse analysis which is concerned primarily with the socio-semiotic functions performed by structures of text and talk. While CDA is largely an interpretative exercise, it places an emphasis on 'triangulation' as a guiding methodological principle intended to help ground analyses and guard against purely subjective readings of texts. In maintaining a commitment to triangulation, CDA has developed a number of multi-methodological approaches combining close text analysis with insights from, inter alia, history, philosophy, political theory, sociology, corpus linguistics and cognitive science. Missing from CDA, however, is triangulation incorporating experimental methodologies. In this paper, I argue that $\mathrm{CDA}$ in general can benefit from an experimental dimension and that Cognitive Linguistic approaches in particular lend themselves to extension into experimentalism. Indeed, experimentation may be seen as the logical 'next step' for cognitive approaches to CDA. I demonstrate this by reporting a recent experiment carried out within a Cognitive Linguistic framework on the effects of regular transactive versus reciprocal verbs in news reports of political protests. In Section 2, then, I discuss in more detail the rationale for experimentation in CDA. In Section 3, I present a discourse-analytical case study which provides the impetus for the experiment reported in Section 4. In Section 5, I offer some conclusions. 
Pre-proof version. Manuscript accepted for publication in Applied Linguistics.

\section{Triangulation, Cognition and Experimentation in CDA}

Critical Discourse Analysis (CDA) is, most fundamentally, a theory of how social action effects arise from the lexico-grammatical 'choices' presented by texts routinely encountered (e.g. Fairclough 1989, 1995; Fowler 1991). CDA therefore involves interpreting the ideological or socio-semiotic functions performed by linguistic structures on specific occasions of use. ${ }^{1}$ Through such detailed linguistic analyses, researchers in CDA hope to reveal (and resist) the ideological and persuasive properties of discourse practices perceived to be dominant (van Dijk 1993). Since its inception, however, a number of now well-known critiques have been made of CDA (e.g. Stubbs 1997; Widdowson 2004). Many of the criticisms raised concern issues of subjectivity in relation to processes of both data selection and interpretation. Specific issues include: 'cherry-picking' and the representativeness of data analysed; biased interpretations based on political predispositions; and over-interpretation or under-interpretation of the cognitive, and thus potentially social action, effects of alternate structures in discourse. As stated by Cameron (2001: 140), then, CDA "is enriched, and the risk of making overly subjective or sweeping claims reduced, by going beyond the single text to examine other related texts and to explore the actual interpretations their recipients make of them". However, many of these concerns, while well-founded, relate only or mainly to the earliest incarnations of CDA in Critical Linguistics (e.g. Fowler et al. 1979; Kress and Hodge 1979). Subsequently, based on principles of triangulation and afforded by new interdisciplinary connections, CDA has indeed developed fresh methods and approaches which go beyond isolated text analyses to explicitly address one or other of these issues.

Triangulation refers to the use of multiple means of inquiry in order to verify results through convergent lines of evidence (Cicourel 1969). This can involve multiple datasets, investigators, theories and/or methods (Denzin 1970). In CDA, triangulation is typically employed in order to guard against issues of subjectivity and thus to help validate analytical interpretations. In the discourse-historical approach, for example, researchers will usually analyse a number of texts belonging to different 'fields of action' or genres, often using focus groups, narrative interviews and other ethnographic techniques to gather different kinds of data alongside more traditional types like policy documents, political speeches and press reports (Kryzyzanowski 2011; Reisigl and Wodak 2001; Wodak and Kryzyzanoswki 2008). Analysing a range of data types helps reduce subjectivity by providing systematic evidence of the discourses which, articulated across text-types, contribute to the structuring of society. Another important means of triangulation now widely practiced in CDA involves the use of corpus-linguistic techniques (e.g. Baker et al. 2008; Gabrielatos and Baker 2008; Koller and Mautner 2004). Enabling large, representative sets of data to be analysed for reoccurring patterns of use, corpus-linguistic methods allow for the dominance of particular discursive practices to be verified, thereby justifying the analyst's focus of investigation in close critical analysis. A further use of corpus-linguistic methods in CDA is in checking the interpretation of particular structures (O'Halloran 2007; Coffin and O'Halloran 2006). For example, by consulting a reference corpus, which functions as a control, the analyst is able to check the inferences and evaluations likely to be associated with language usages found in the target corpus. One further form of triangulation recently found in CDA is the use of inter-analyst consistency tests (e.g. Baker in press; Baker and Levon 2015; Marchi and Talyor 2009). In the study by Baker (in press), for example, five analysts

\footnotetext{
${ }^{1}$ Note that this is not to attribute the same socio-semiotic function to a given linguistic structures across all its contexts of use (van Dijk 2008: 823).
} 
Pre-proof version. Manuscript accepted for publication in Applied Linguistics.

worked independently of each other on the same set of newspaper texts. The five analysts were also free to choose their own methodologies in conducting the analyses. The reports of the five analysts were then compared and quantified in order to reveal common findings. Baker notes that around a quarter of observations were shared by at least three of the five analysts. Such consistency tests help reduce subjectivity by pointing to features of the texts found to be significant by multiple researchers and through multiple methodological means. What these works all point to is a general trend in CDA toward adopting more empirical methods such that what characterises contemporary CDA, as Weiss and Wodak (2007: 22) note, is an "endeavour to work interdisciplinarily, multimethodically and on the basis of a variety of different empirical data".

One further development in contemporary CDA is found in cognitive approaches (e.g. Chilton 2004, 2005; O'Halloran 2003; van Dijk 1998, 2008, 2010). It is now increasingly recognised that any causal relation between language and social action is necessarily mediated by cognition (Wodak 2006). This is formulated as the discourse-cognition-society triangle (van Dijk 1999, 2014). Various forms of cognitive structure and process have been proposed to operate at the interface between language use and social action (van Dijk 2008, 2010; Koller 2008, 2012; Hart 2010, 2014a). What authors in cognitively-oriented CDA agree on, however, is that the structures and processes which mediate between discourse and social action are multifaceted, integrating knowledge, values, norms, goals, motives, emotions and decisions. Within cognitively-oriented CDA, then, the ideological or sociosemiotic effects of texts are seen as ultimately constituted in their cognitive effects. It is important to recognise here that the cognitive processes studied in cognitive CDA do not equate with 'rational' processes but, rather, 'cognitive' encapsulates a range of mental phenomena including cognitive and affective processes (Damasio 1994). By cognitive effect, then, it is meant changes, based on exposure to certain language usages, in processes of comprehension, memory, attention, emotion, social perception, reasoning and decision-making etc. These cognitive processes are all involved in discursively constructing the worldviews on the back of which social actions are performed or supported.

One cognitive approach to CDA which has recently developed involves the application of Cognitive Linguistics (Charteris-Black 2004; Chilton 2004, 2005; Hart 2010, 2011a, 2013a/b, 2014a/b, 2015; Koller 2004, 2008, 2014). Cognitive Linguistic approaches to CDA are characterised by detailed semantic description of lexical, grammatical and textual 'constructions'. Specifically, Cognitive Linguistic CDA (CL-CDA) involves modelling the conceptual structures invoked by language usages and, in turn, considering the potential ideological functions or implications of those conceptual structures (Hart 2014a). In other words, it involves a socio-semiotic analysis of semantic characterisations of linguistic forms. This, arguably, presents a more empirical approach to CDA in so far as analyses are grounded in a principled, psychologically plausible model of language processing, given what is already known from other disciplines about the way the mind/brain works (Langacker 1999). In so far as the semantic characterisations given of specific linguistic structures are taken from or motivated by analyses made within an apolitical field of linguistic inquiry, this approach also helps reduce the risks of subjectivity and over-interpretation (Hart 2014a). Grounding text analyses in Cognitive Linguistics, though, does not itself constitute triangulation. The analyses, or the predictions made by them, still need to be verified.

One way of doing this is through experimentation. Experimental methods, however, are missing as a form of triangulation in CDA. As O'Halloran (2005: 342) states, "socio-cognitive analysis in CDA is not 
Pre-proof version. Manuscript accepted for publication in Applied Linguistics.

always empirically informed ... and thus may wrongly assume that the critical discourse analyst is replicating the reading perspective of target readers". This is in spite of frequent calls in CDA for data empirically demonstrating the ideological effects of texts. Fairclough (1995: 9), for example, highlights as a problem "analysts who postulate ideological effects solely on the basis of analysis of texts without considering the diverse ways in which texts may be interpreted and responded to". O'Halloran (2003: 219) writes that "it is difficult to argue that analysts do not have to seek empirical justification for their socio-cognitive analysis of a text based on an ideal reader". Of course, there are other ways besides experimentation to address the issue of audience reception. For example, by analysing blogs, comments sections etc. or by holding focus groups, which could demonstrate how a text is 'taken up' by participants in the communicative event. Experimental methods, however, provide one further line of convergent (or otherwise) evidence and can thus contribute to triangulation. One reason that experimental methods may not be found in CDA is that "empirical psycholinguistic, causal-cognitive analysis of hard news is so difficult and cumbersome to achieve" (O'Halloran 2005: 342). Another is that experimental methods may be misinterpreted as trying to reduce complex social processes to something that can be studied in a laboratory where the results of such decontextualisation will necessarily be artificial. However, it is not the aim of conducting experiments in CDA to claim that the social, political and historical dimensions of discourse are not important in the way that texts are interpreted. Rather, it is to recognise that the cognitive dimension is of equal importance and in so doing to answer particular criticisms of CDA by showing that alternative structures in discourse can, at least at the moment of interaction with the text, achieve cognitive effects. ${ }^{2} \quad$ Moreover, while experimentation does unavoidably involve decontextualisation, such an 'all else being equal' kind of analysis is nevertheless valuable for CDA. A significant challenge for CDA is to go beyond theorising the instrumentality of language to showing that language choices really do matter. While the social action effects of texts can never, of course, be directly observed, the cognitive effects of language use are observable. That is, while the link between language and social action is difficult to prove, the link between language and cognition is within empirical reach. And since any social action effects of texts are necessarily contingent on cognitive effects, it is worth investigating the cognitive effects of texts in order (i) to verify the very possibility that language can have consequences in social action and not break the first link in the discourse-cognition-society triangle and (ii) to validate CDA's focus on, and interpretation of, particular lexico-grammatical structures in discourse. Such an approach to CDA falls in line with Weiss and Wodak's definition of triangulation through which, they state, researchers in CDA aim to "transcend the pure linguistic dimension and include more or less systematically the historical, political, sociological and/or psychological dimension in the analysis and interpretation of a specific discursive occasion" (2007: 22, my emphasis). Since Cognitive Linguistic approaches to CDA are most directly concerned with, and make testable predictions about, the cognitive import of language usages, it is Cognitive Linguistic approaches to CDA more than any other which lend themselves especially well to extension into experimentalism.

\footnotetext{
${ }^{2}$ Of course, readers are free to later update, delete or replace their mental representations and/or adjust their value positions (Chilton 2004; Hart 2011b). However, repeated patterns in influential genres of discourse make certain representations cognitively more accessible and thus more costly, in terms of processing efforts, to question or counter (Maillat and Oswald 2011; Oswald and Hart 2014). Here, corpus linguistic methods may be usefully incorporated.
} 
Pre-proof version. Manuscript accepted for publication in Applied Linguistics.

One area of communication research where experimental methods have been successfully applied is in relation to news frames. In media studies, a frame is defined as a 'central organising idea' around which a text hangs (Entman 1993; Gamson and Modigliani 1989). For example, press reports on political protests tend to be structured in terms of a violence rather than, say, an injustice frame (Boykoff 2006; Hacket and Zhou 1994; McLeod and Hertog 1992). Different frames makes salient different aspects of a story and in so doing achieve different kinds of cognitive, or framing, effect. Framing effects have been shown, for example, in information processing and memory recall (Newhagen and Reeves 1992), attitude (Nelson et al. 1997) and the formation of opinions and behavioural intentions (Schuck and de Vreese 2006). ${ }^{3}$ Entman (1993: 52) identifies as the textual properties through which frames are manifested "the presence or absence of certain keywords, stock phrases, stereotyped images, sources of information and sentences that provide thematically reinforcing clusters of facts or judgements". While research in this area, then, demonstrates empirically the power of frames in influencing cognition, where frames are understood as macroconcepts governing the thematic contents of a text, comparatively little research has been conducted on framing effects of the more subtle and specific lexico-grammatical distinctions characteristically analysed in CDA, which may be said to index or invoke alternative event-frames (see section below).

Two papers which do examine the cognitive effects of specific lexico-grammatical phenomena are Fausey and Matlock (2011) and Thibodeau and Boroditsky (2011). Fausey and Matlock investigated the effects of aspect in describing some indiscretion of a fictional politician. They found that subjects presented with the perfective aspect rated the politician's chances of re-election as higher than subjects presented with the imperfective aspect. Thibodeau and Boroditsky tested the effects of metaphor in communication about crime. They found that subjects presented with a CRIME AS WILD BEAST metaphor were more likely to suggest redressive measures relating to enforcement (capture, punish etc.) while subjects presented with a CRIME AS VIRUS metaphor were more likely to suggest redressive measures relating to reform (diagnose, treat, etc.). In other words, the metaphors had an effect on respondents' reasoning and decision-making processes with suggestions on how to address crime being found to fit with the particular metaphorical framing given. Studies such as these are clearly relevant for CDA and may provide useful templates for experimental design. They suffer one serious problem from a CDA perspective, however, which is that they are not based on attested discourse practices discerned from a specific discourse-analytical case study. Any experiment in CDA must, by contrast, start from hypotheses made on the back of qualitative analyses of observed (differences in) discourse data. In the following section, I therefore present a Cognitive Linguistic analysis of online newspaper data with a focus on the alternative event-frames used to conceptualise violent interactions at political protests. The analysis provides the basis of and motivation for the experiment reported in the following section.

\footnotetext{
${ }^{3}$ Such framing effects have been shown for visual as well as verbal texts (e.g. Arpan et al. 2006; Coleman 2010; Powell et al. 2015).
} 
Pre-proof version. Manuscript accepted for publication in Applied Linguistics.

\section{Discourse-Analytical Case Study}

The starting point in this paper, then, is a series of studies on media representations of political protests (Hart 2013a/b, 2014a/b, in press a/b). One striking finding from these studies concerns the use of reciprocal versus regular transactive form constructions (involving verbs or nominalised equivalents) to report the same violent interaction between police and protesters. In a study of the 2010 student fee protests (Hart 2013b), for example, it was found that in reporting interactions construed as ACTION events (as opposed to FORCE or MOTION events) in which the protesters were agentive, newspapers on the left of the political spectrum, such as the Guardian ( $n=6)$, favoured the use of reciprocal forms as in (1) below while newspapers on the political right, such as the Telegraph $(n=7)$, preferred regular transactive forms as in (2). The results for the Guardian versus the Telegraph are reproduced in Figure 1.

(1) Activists who had masked their faces with scarves traded punches with police. (Guardian, 10 November 2010)

(2) A number of police officers were injured after they came under attack from youths, some wearing scarves to hide their faces. (Telegraph, 10 November 2010)

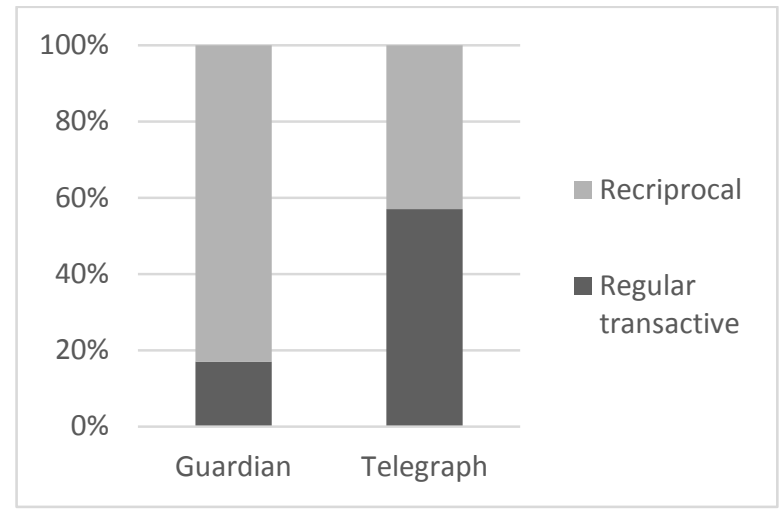

Figure 1. \% of ACTION events in which protesters are agentive encoded with regular transactive versus reciprocal verbs.

A further distinction found between newspapers on the political left versus right concerns information sequence within reciprocal form constructions. Consider the contrast between (3) and (4) by way of example. In a study of the 2009 G20 and the 2010 Student Fee protests (HART 2013a), it was found that when reciprocal forms (in which the actors were included in the clause) were used, the Telegraph $(n=4)$ preferred $(75 \%)$ to place the protesters before the police in the linear organisation of the clause while in the Guardian $(n=5)$ the protesters appeared earliest in the clause on only two occasions (40\%). These findings are shown in Figure 2.

(3) [police wielding batons] clashed with [a crowd hurling placard sticks, eggs and bottles] (Guardian, 10 November 2010) 
Pre-proof version. Manuscript accepted for publication in Applied Linguistics.

(4) Twenty-three people were arrested as [protestors] clashed with [police] around the Bank of England. (Telegraph, 1 April 2009)

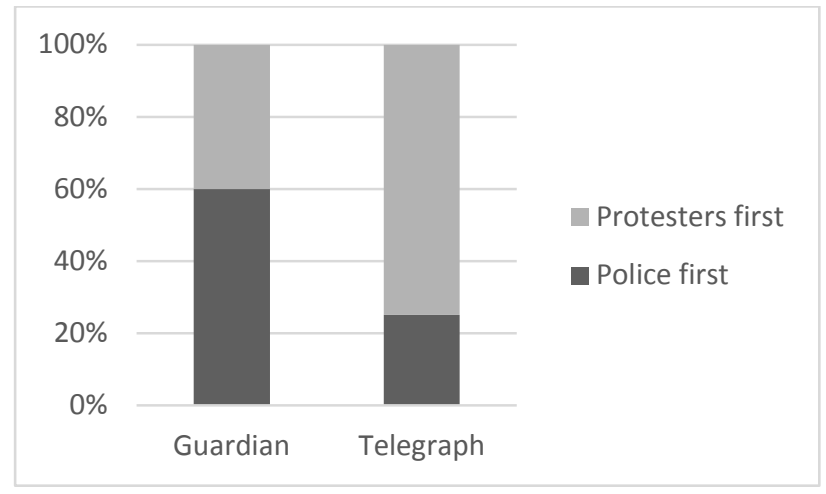

Figure 2. Information sequence in reciprocal form constructions

One final distinction lies in the voice of regular transactive verb constructions. In the student fee protest data, a contrast could be seen in the right-wing press between active and passive voice which depended on whether the police were agents or patients in interactions construed as violent (ACTION) or non-violent (FORCE or MOTION). For example, in the Mail, another right-wing newspaper, when the police were patients in violent interactions $(n=4)$ it was the passive voice, as in example (2), that was preferred (75\%) but when they were agents in force or motion events as in (5) and (6) $(n=15)$, the active voice was preferred (80\%).

(5) About three dozen police officers were blocking the entrance to the town hall (Mail, 24 November 2010)

(6) Officers led them down from various floors of the seven-storey building (Mail, 10 November 2010)

Although, based on such small samples of data, none of these results would be statistically significant, they do show clear, divergent patterns of distribution which, from a critical cognitive perspective, suggest that the alternate grammatical constructions belong to alternative repertoires in political protest reporting and may therefore be ideologically significant in encoding contrasting conceptualisations which instantiate competing worldviews. ${ }^{4}$

Within a Cognitive Linguistics framework, alternate grammatical constructions are seen as indexing and invoking alternative event-frames (Fillmore 1982; Ruppenhofer et al. 2010; Talmy 2000). An event-frame is different to a news frame in so far as it does not constitute a general value-oriented concept around which a text is constructed but, rather, represents a basic unit of experience in terms of which specific interactions get classified and understood. An event-frame is defined by Talmy as "a set of conceptual elements and interrelationships that are evoked together or co-evoke

\footnotetext{
${ }^{4}$ At this point, it would be worthwhile to 'up-sample' and investigate whether the pattern found in such small scale analyses is found to be statistically significant within a large corpus of data. Such an approach would be in line with the kind of triangulation practiced in corpus approaches to CDA. To do so, however, would take us beyond the limits of this paper.
} 
Pre-proof version. Manuscript accepted for publication in Applied Linguistics.

each other" (2000: 259) in order to provide coherence and organisation to a scene and to distinguish it from other types of scene. Event-frames, thus, represent specific kinds of interaction between actors and objects in the world. They are evoked by different lexico-grammatical constructions, where the conceptual elements that make up an event-frame correspond with the semantic roles specified in a verb's canonical argument structure. The most basic event-frames are conceptually represented in the form of image schemata (Langacker 1987, 1991, 2008).

Crucially, as in other forms of framing, alternative event-frames are available to conceptualise the same material situation in different ways. Regular transactive versus reciprocal constructions, for example, are analysed as invoking a one-sided versus a two-sided action event-frame respectively. In a one-sided action event-frame, there is a unidirectional transfer of energy from an AGENT (A), 'upstream' in the energy flow, to a PATIENT (P) 'downstream' in the energy flow. In such a conceptualisation, the AGENT is the sole source of energy in the interaction while the PATIENT is the energy sink. ${ }^{5}$ In a two-sided action event-frame, by contrast, there is a bidirectional flow of energy between the two participants each of whom are encoded as agentive. As such, in a two-sided action event-frame both participants are simultaneously an energy source and sink in the interaction. The two contrasting event-frames are modelled in Figure 3.
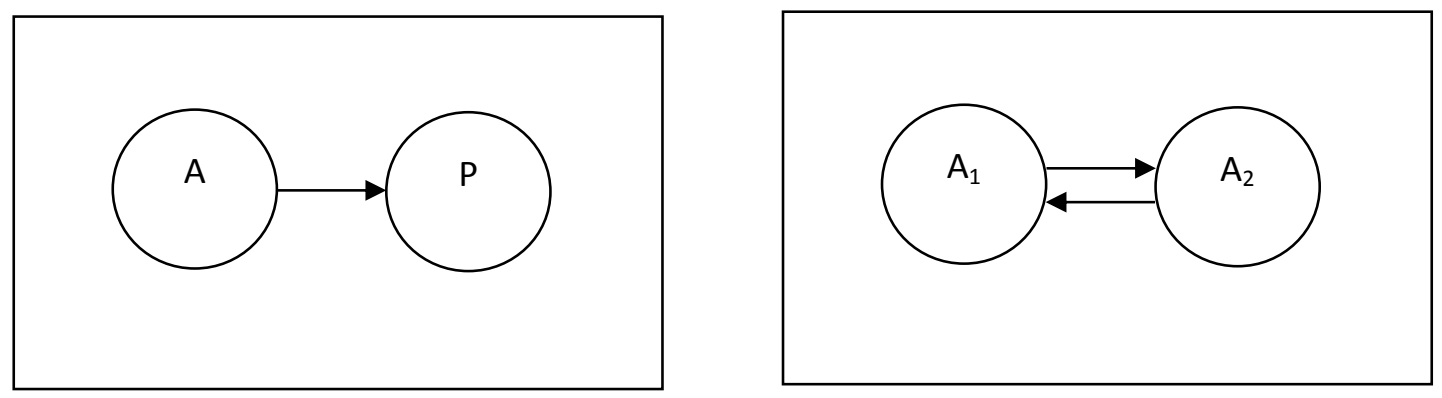

Figure 3. One-sided versus two-sided action event frame

From a critical perspective, in the context of discourse on political protests, these alternative conceptualisations serve to apportion blame and responsibility for violent encounters in different ways. In the two-sided action event-frames favoured by the Guardian, responsibility is shared more equally between the police and the protesters while in the one-sided action event-frame favoured by the right-wing press responsibility is assigned solely to the protesters with the police presented as victims of the violence. These contrasting conceptualisations can therefore be interpreted as indexical of competing ideologies or worldviews concerning the relation between State and Citizen, the role of the police in maintaining public order, and the (de)legitimacy of protest as a form of political action. The one-sided action event-frames found in the right wing press may be said to reflect a worldview in which the police are seen as legitimate defenders of civil order while protest is seen as a deviation from normative behaviour (Hall 1973: Murdock 1973). By contrast, the twosided action event-frames found in the Guardian may be said to at least recognise a discourse in which the police are seen as more authoritarian figures interfering with the right to public political expression.

\footnotetext{
${ }^{5}$ The transfer of energy from AGENT to PATIENT may be via an INSTRUMENT which thus acts as a 'transmitter'.
} 
Pre-proof version. Manuscript accepted for publication in Applied Linguistics.

A further feature of conceptualisation consists in point of view as many, if not all, grammatical constructions include as part of their semantic values a viewpoint specification (Langacker 2008; Bergen 2012). That is, the event-frame activated is construed from a particular vantage point or point of view (PoV). Hart (2014a, 2015) models this in terms of PoV shifts in one of three dimensions: ANCHOR, ANGLE and DISTANCE. He argues that the distinction between active and passive voice in regular transactive constructions and information sequence in reciprocal constructions can be characterised in terms of a PoV shift in the ANCHOR aspect. On this account, the active voice in regular transactive constructions is analysed as encoding a PoV in line with the perspective of the AGENT upstream in the energy flow. The passive voice is analysed as encoding a PoV in line with the perspective of the PATIENT downstream in the energy flow. Reciprocal verbs, by contrast, are analysed as encoding a PoV perpendicular to the flow of energy such that the conceptualiser comes to form a triangular relation with actors in the event-frame. Motivated by an iconic relation between sequential ordering in the clause and spatial ordering in the conceptualisation (Perniss, Thompson and Vigliocco 2010), differences in information sequence are then analysed as encoding contrasting PoVs which reverse the left-right configuration of actors relative to the conceptualiser. Thus, while the information sequence in (3) locates the police to the left of the conceptualiser and the protesters to the right, the sequence in (4) places the protesters to the left and the police to the right. These four cardinal points of view are modelled in Figure 4.
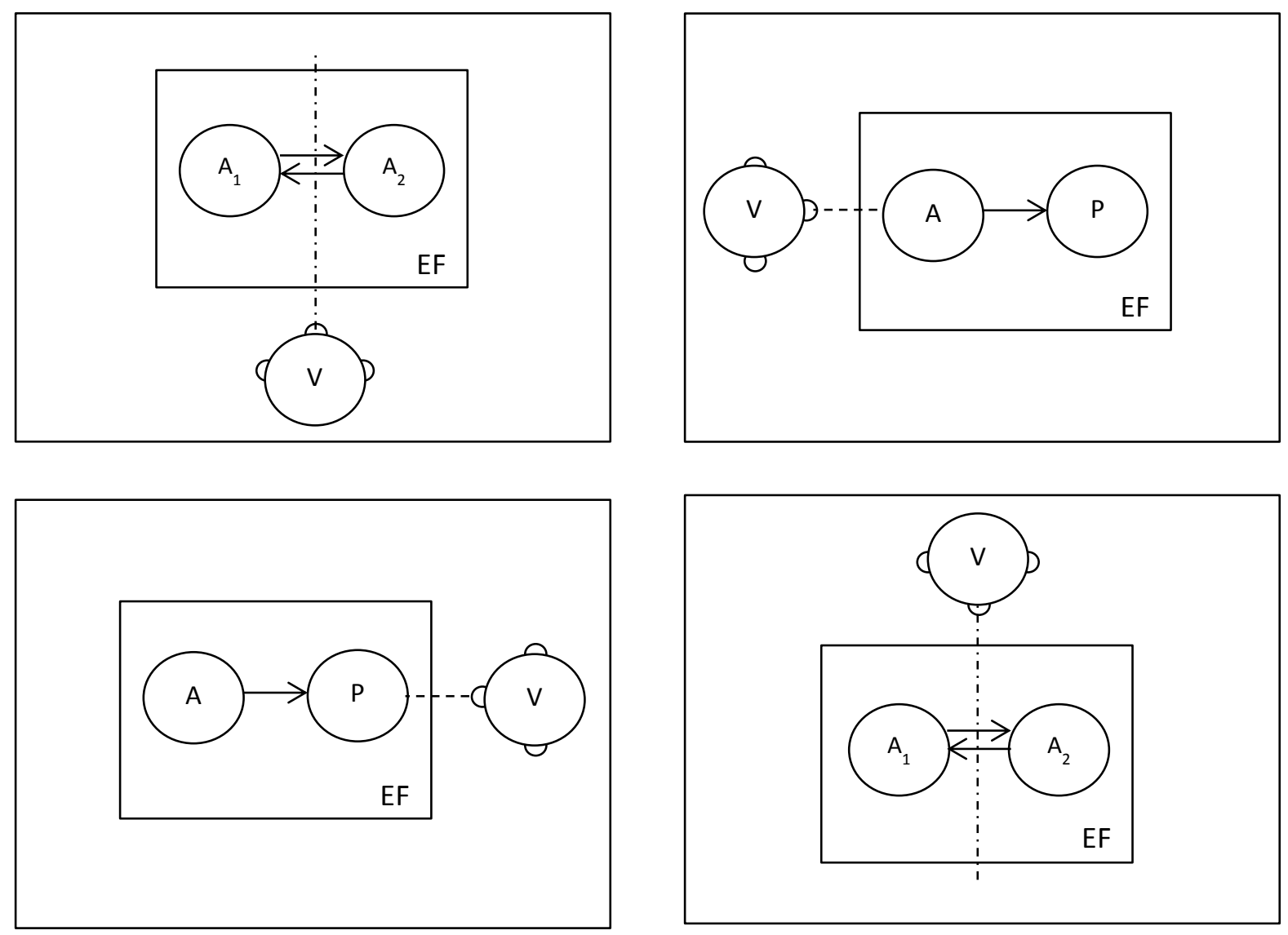

Figure 4. Point of view variables in conceptualisation 
Pre-proof version. Manuscript accepted for publication in Applied Linguistics.

In critically interpreting the function of PoV, Hart (2014a, 2015, in press a/b) draws connections with both embodiment and visual social semiotics. He argues that, from the PoV of the AGENT in active voice constructions, the conceptualiser is more likely to affiliate with the AGENT and see their actions as legitimate while from the shared perspective of the PATIENT in passive voice constructions the conceptualiser is more likely to affiliate with the PATIENT and see the actions of the AGENT as antagonistic. In the case of reciprocal constructions, although comparatively more neutral and less 'involved' (cf. Kress and van Leeuwen 2006), it is argued that the alternative right-left positioning of participants confers upon them more positive versus negative evaluations respectively. Historically, for example, left is symbolically associated with bad while right is associated with good (McManus 2003). Similarly, within the body-specificity hypothesis, it has been experimentally shown that left is typically associated with negative valence while right is typically associated with more positive valence (Casasanto 2009).

The case study reported in this section suggests some pragmatic significance in the use of regular transactive versus reciprocal constructions in media discourse on political protests. Distributional differences observed in data of different political orientation suggest that these grammatical forms are a conventional part of alternative repertoires in the reporting of violence at political protests and that these competing forms may therefore perform some ideological function in this context. Qualitative analysis within a CL-CDA framework, in turn, attributes specific, contextually bound, ideological or socio-semiotic functions to these forms. These analyses amount to hypotheses concerning cognitive responses of readers. The extent to which these alternate forms actually succeed in achieving any cognitive effects, however, remains uncorroborated. In the following section, therefore, by way of triangulation, I report an experiment testing the cognitive effects of reciprocal versus regular transactive verbs in the context of discourse on political protests.

\section{Experiment}

\subsection{Participants}

A total of 152 participants took part. Participants were recruited using Reddit's r/SampleSize (https://www.reddit.com/r/SampleSize/). $r$ /SampleSize is an online platform dedicated to scientific, fun and creative surveys comparable to Amazon's Mechanical Turk. ${ }^{6}$ Unlike Amazon's Mechanical Turk, participants recruited through $r$ /SampleSize receive no payment. However, Buhrmester et al. (2011) report that participants in online research are internally (e.g. for enjoyment) rather than financially motivated. This suggests that the quality of data from online samples might actually be higher than from more traditional samples (ibid.). Indeed, a number of studies now attest to the reliability of psychological research conducted over the internet (Behrend et al. 2011; Crump et al. 2013; Germine et al. 2012; Klein et al. 2014; Mason and Suri 2012; Paolacci et al. 2010; Woods et al. 2015). A particular advantage of online research in the context of news communication is that it presents a more ecologically valid scenario, at home in front of a computer, for the way many people now read the news (Ofcom 2014). Another significant advantage is that, compared with the population available at Lancaster University, and university campuses more generally, gathering data online also enables a broader cross-section of society to be sampled (Buhrmester et al. 2011;

\footnotetext{
${ }^{6}$ Mechanical Turk is not currently available to researchers outside the United States.
} 
Pre-proof version. Manuscript accepted for publication in Applied Linguistics.

Henrich et al. 2010). Participants were therefore deliberately not restricted in terms of factors like age, gender, geographical location, political affiliation, education or first language, so as to more realistically reflect populations of news consumers. This is particularly important if one wants to investigate the potential impact of media discourses. However, at the end of the study participants were asked a number of questions relating to demographics. The characteristics of the sample are given in Table 1.

\begin{tabular}{cccccccccccc}
\hline & \multicolumn{2}{c}{ Age-Range } & & & Gender & & \multicolumn{2}{c}{ First Language } & \multicolumn{2}{c}{$\begin{array}{c}\text { Political } \\
\text { Affiliation }\end{array}$} \\
\hline $16-24$ & $25-44$ & $45-64$ & $65+$ & Male & Female & Other & English & Other & $\begin{array}{c}\text { Lab } \\
\text { (Dem) }\end{array}$ & $\begin{array}{c}\text { Con } \\
\text { (Rep) }\end{array}$ \\
\hline 76 & 62 & 12 & 2 & 83 & 67 & 2 & 132 & 20 & 122 & 30 \\
\hline
\end{tabular}

Table 1. Participant Characteristics

\subsection{Materials and Design}

Participants were presented with a survey that included a short (one paragraph) news report about a recent political protest in the fictional city of Southfield. When participants had indicated that they had read the report, the report disappeared and they were asked a series of three follow-up questions. No 'back' button was given inside the survey and participants were instructed not to use the 'back' button on their web browser. This ensured that participants did not re-read the report when answering the follow-up questions. The task was one of four in total with the other three being unrelated to this study.

Participants were presented with one of four versions of the report which differed only in their use of regular transactive versus reciprocal verb constructions as well as voice and information sequence within these categories. The precise formulation of these variables was guided by the examples found in Hart (2013a/b) and discussed in section 3 above. The rest of the text was similarly designed to follow as closely as possible the narrative structure of attested protest reports analysed in these studies. The data is therefore 'near-authentic'. Each report contained two instances of the constructions under consideration. The four reports read as follows:

\section{Report 1}

A protest against local council policy turned violent yesterday in the city of Southfield. Protesters attacked police officers amid scenes of chaos outside City Hall. The protest later moved to the central square where protesters continued to assault police officers. Police officers used batons to control the crowds, which eventually dispersed around 9pm. 10 people received treatment for injuries.

\footnotetext{
${ }^{7}$ Participants were asked to state which party they most affiliated with between Labour versus Conservatives (UK) and Democrats versus Republicans (US).
} 
Pre-proof version. Manuscript accepted for publication in Applied Linguistics.

\section{Report 2}

A protest against local council policy turned violent yesterday in the city of Southfield. Police officers came under attack from protesters amid scenes of chaos outside City Hall. The protest later moved to the central square where police officers continued to be assaulted by protesters. Police officers used batons to control the crowds, which eventually dispersed around $9 \mathrm{pm} .10$ people received treatment for injuries.

\section{Report 3}

A protest against local council policy turned violent yesterday in the city of Southfield. Protesters clashed with police officers amid scenes of chaos outside City Hall. The protest later moved to the central square where protesters continued to trade punches with police officers. Police officers used batons to control the crowds, which eventually dispersed around $9 \mathrm{pm} .10$ people received treatment for injuries.

\section{Report 4}

A protest against local council policy turned violent yesterday in the city of Southfield. Police officers clashed with protesters amid scenes of chaos outside City Hall. The protest later moved to the central square where police officers continued to trade punches with protesters. Police officers used batons to control the crowds, which eventually dispersed around $9 \mathrm{pm} .10$ people received treatment for injuries.

Report 1 was received by 31 participants, Report 2 by 37 participants, Report 3 by 43 participants and Report 4 was received by 41 participants. ${ }^{8}$ All four reports were followed up by the same three questions. These questions were motivated by hypotheses emerging from the case studies reported in Section 3 and were intended to determine specific cognitive effects predicted by the analyses. The following questions were presented in random order:

(1) Where would you place the blame for the violence that occurred?

(2) How aggressive do you think the protesters were?

(3) How aggressive do you think the police were?

Participants answered Q1 on a five-point Likert scale <Protesters Fully to Blame - Protesters Mainly to Blame - Both Parties Equally to Blame - Police Mainly to Blame - Police Fully to Blame>. Participants answered Q2 and Q3 on a seven-point Semantic Differential scale with bipolar evaluations <Not Aggressive at All - Extremely Aggressive>. Since neither question types yielded normal distributions, non-parametric tests were used in the statistical analyses. For Q1, involving nominal values, analysis was carried out using Chi-square with a significance level set at $p<.05$. For Qs 2 and 3 involving ordinal values, analysis was carried out using Mann-Whitney $U$ with significance level again set at $p<.05$. All and only participants who completed the whole survey were included.

\footnotetext{
${ }^{8}$ The uneven distribution is due to two main factors: the random assignment of the reports by the survey software and the inclusion of only fully completed surveys.
} 
Pre-proof version. Manuscript accepted for publication in Applied Linguistics.

\subsection{Results}

In Q1 participants were asked to assign blame for the violence that occurred. It was hypothesised that blame would be assigned more evenly in the two-sided action event-frame invoked by reciprocal constructions than in the one-sided action event-frame invoked by regular transactive constructions. Overall, there was a significant difference in how participants responded $\chi^{2}=$ $32.3911, p<.00001)$. Participants given the regular transactive condition with protesters as the sole agent in the event-frame (Reports 1 and 2) were more likely to see the protesters as either fully $(22 \%)$ or mainly $(54 \%)$ to blame and less likely to assign equal blame $(18 \%)$. Very few participants viewed the police as shouldering any blame (mainly $=6 \%$, fully $=0 \%$ ). Conversely, in the reciprocal condition (Reports 3 and 4), participants were much more likely to apportion equal blame to actors in the event (45\%). Moreover, of those participants who did assign more blame to one actor over the other, there was a fairly even distribution (protesters fully to blame $=6 \%$, protesters mainly to blame $=25 \%$, police mainly to blame $=23 \%$ and police fully to blame $=1 \%$ ). The results for Q1 are shown in Figure 5 with the two points 'fully to blame' and 'mainly to blame' on the Likert scale conflated into a single category.

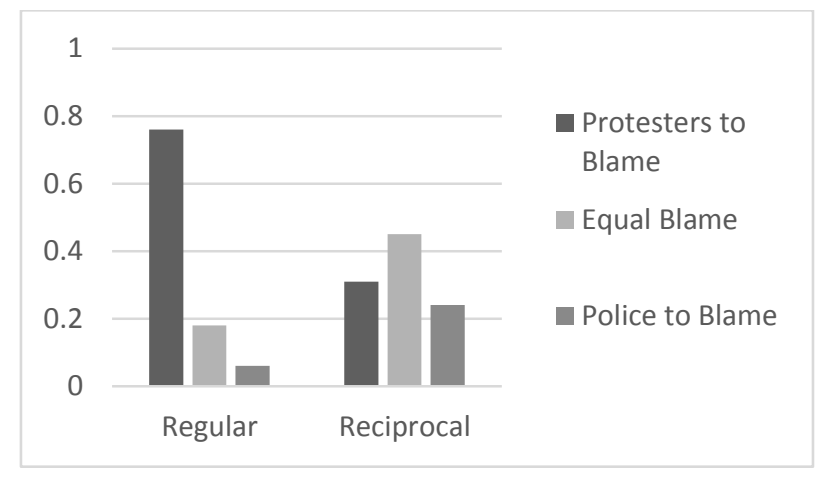

Figure 5. Blame attribution in regular versus reciprocal constructions

Although participants given reciprocal verb constructions were more likely to apportion blame evenly, a difference could be seen between those participants who did assign more blame to one actor over the other which depended on information sequence. As shown in Figure 6, participants given the protester-first version (Report 3 ) were more likely to place the blame with the protesters $(46 \%)$ than the police (11\%) while the converse was observed for participants given the police-first version (Report 4) who were more likely to place the blame with the police (36\%) than the protesters $(15 \%)\left(\chi^{2}=13.5761, p<.01\right)$. 
Pre-proof version. Manuscript accepted for publication in Applied Linguistics.

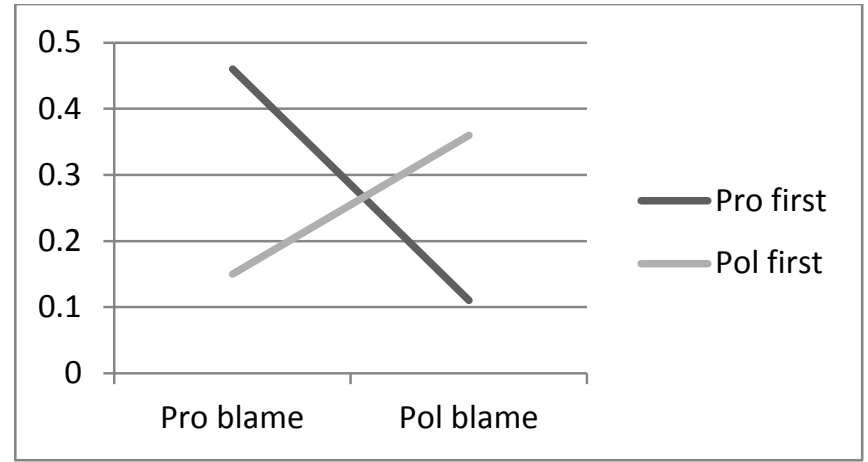

Figure 6. Blame attribution in two-sided event-frames Pro=protesters, Pol=police

In Qs 2 and 3, participants were asked to evaluate the aggressiveness of actors in the event on a seven point semantic differential scale. It was hypothesised that aggression ratings would differ according to whether the event is construed in terms of a one-sided versus a two-sided action eventframe and, in turn, according to shifts in point of view prompted by voice and information sequence. Overall, as expected, results show that police are rated as more aggressive in response to reciprocal constructions than regular transactive constructions in which they are the patient $(U=1436$, $p<.00001)$. Conversely, protesters are rated as less aggressive in response to reciprocal constructions than regular transactive constructions in which they are the agent $(U=1893, p<.001)$. These results are shown in Figure 7. Interestingly, it is worth noting that when they occur in a twosided action event-frame - compare Figure $7(b)$ and $(d)$ - the police are rated as more aggressive than protesters $(U=2829, p<.05)$. 
Pre-proof version. Manuscript accepted for publication in Applied Linguistics.

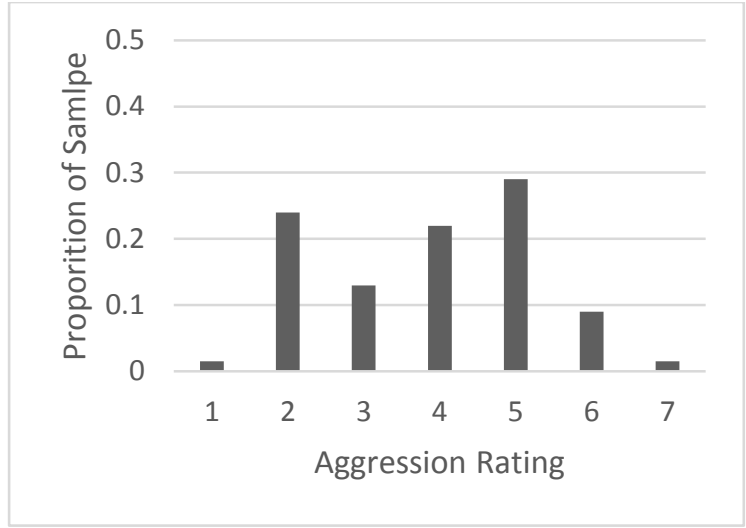

(a) police aggression, regular construction

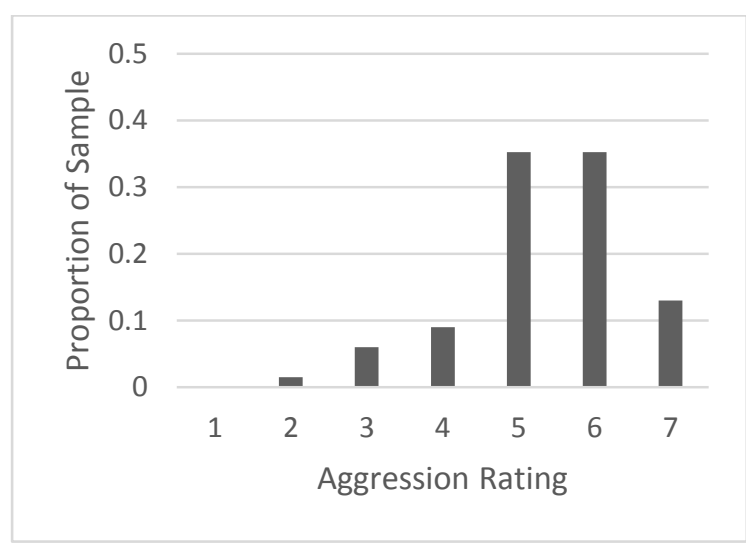

(c) protester aggression, regular construction

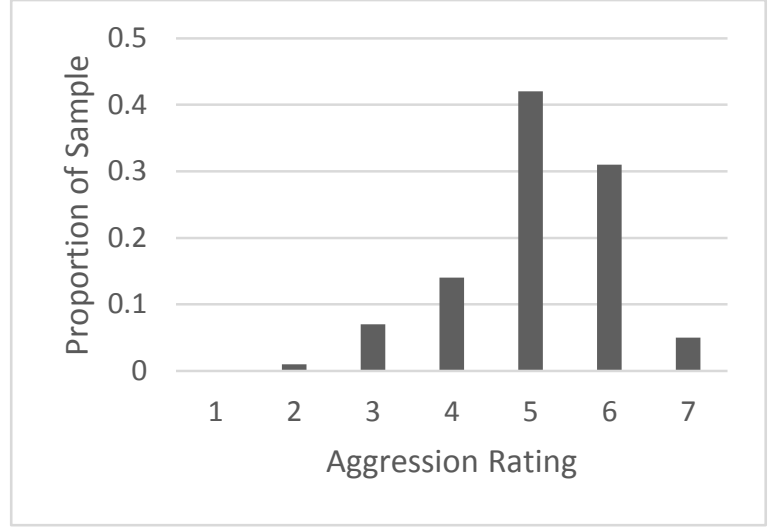

(b) police aggression, reciprocal construction

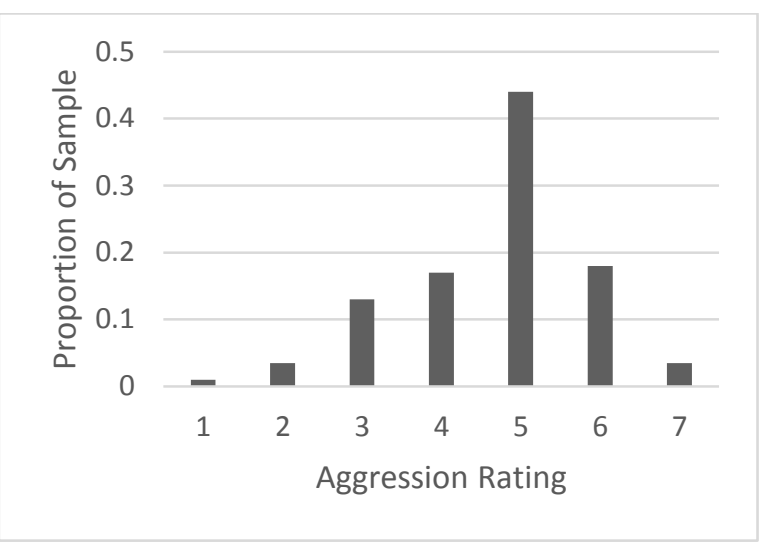

(d) protester aggression, reciprocal construction

Figure 7. Aggression ratings for police and protesters in reciprocal versus regular transactive constructions

Within reciprocal constructions, it is predicted that information sequence, as a consequence of relative left-right arrangements of actors in the event-frame, will result in slight differences in the level of aggression attributed to actors. This is indeed observed where, as shown in Figure 8(a), when the protesters appear first in the clause they are rated as more aggressive by more participants than when they appear second. Although this particular result is not statistically significant $(\mathrm{U}=898.5, p=.06432 \mathrm{~ns})$ it is indicative that a similar pattern is observed in relation to the police which, shown in Figure $8(b)$, is statistically significant $(U=545.5, p<.01)$. 
Pre-proof version. Manuscript accepted for publication in Applied Linguistics.

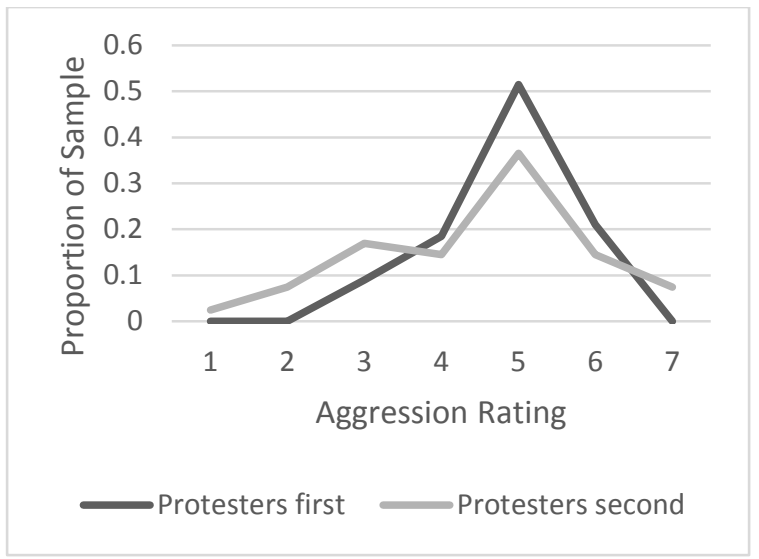

(a) protester aggression

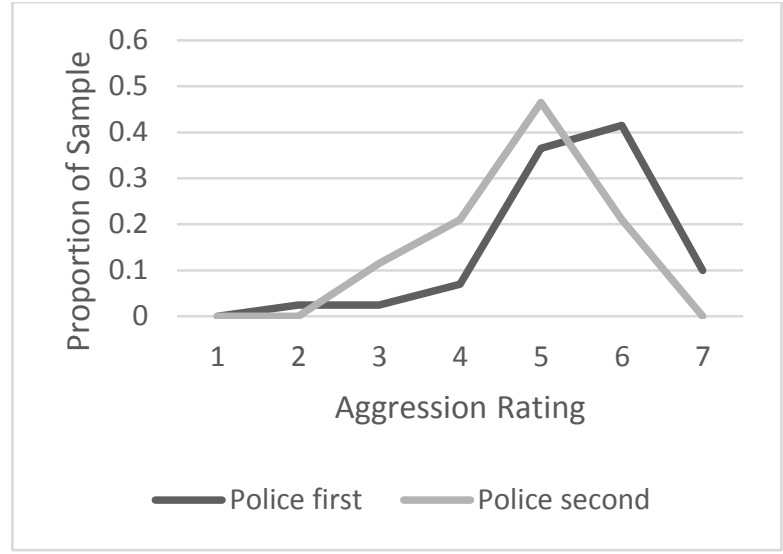

(b) police aggression.

Figure 8. Aggression ratings for police and protesters in reciprocal constructions

The final prediction to emerge from the analyses in Section 3 is that in regular transactive constructions the agent, in this case the protesters, will be rated as more antagonistic in the passive voice than in the active. However, there was no difference in aggression rating between voice alternates $(U=555, p=0.82588 n s)$.

\subsection{Discussion}

In this experiment, I have investigated the cognitive effects (specifically blame allocation and social perception of aggression) of alternate action event-frames indexed in regular transactive versus reciprocal verb constructions and point of view shifts indexed in voice and information sequence in media discourse on political protests. It was found that conceptualising interactions between police and protesters in terms of a one-sided action event-frame leads to blame being placed predominantly with the agent (in this case the protesters). Conceptualising the same interaction in terms of a two-sided action event-frame leads to blame being more equally assigned. At the same time, police are perceived as more aggressive in a two-sided action event-frame than when in the role of patient in a one-sided action event frame. And protesters are perceived as more aggressive when they are agents in a one-sided action event-frame than when they are agents in a two-sided action event-frame. It seems, then, that the presence of the police as an agent in a two-sided action event-frame serves not only to increase the perceived level of aggression for the police but, by the same token, to downplay perceived level of aggression of protesters relative to a one-sided action event-frame in which they are the sole agent. It was further found that when the police appear as agents in a two-sided action event-frame, they are perceived as more aggressive than protesters. Within a two-sided action event-frame, actors appearing first in the linear organisation of the clause and therefore on the left in the event-frame received more blame for the violent encounter and were perceived as more aggressive than the actor appearing second in the clause and therefore on the right in the event-frame. This is in line with predictions made on the back of the body-specificity hypothesis (Casasanto 2009). Interestingly, however, the effect on aggression perception was greater in relation to the police than in relation to protesters. This, along with overall higher aggression ratings for police than protesters in a two-sided event-frame may be due to the challenge that this conceptualisation presents to the prevailing discourse of police as protector. No similar 
Pre-proof version. Manuscript accepted for publication in Applied Linguistics.

effect was found for voice alternates in one-sided action event-frames. This may be due to a number of reasons. One, however, is that humans are extremely good at perspective-switching (MacWhinney 2008) and this may serve to cancel out any effect that voice might have on point of view. Either way, the results suggest that voice might not be the most important linguistic feature affecting how an event is conceptualised.

Overall, though, the results of this experiment do show that subtle lexico-grammatical differences make a significant difference in how readers interpret and respond to the same story. In this, as perhaps expected, it is aspects of language usage traditionally thought of as more semantic that make the most difference but, in line with other studies (e.g. Fausey and Matlock 2011), grammatical properties are shown to matter too.

Of course, people do not process texts free of a priori assumptions and value positions (Widdowson 2004). Political orientation may therefore be a contributing factor in how people respond to texts. Participants in the experiment were thus asked to express their political affiliation at the end of the survey. When we compare across political affiliation, however, we find it is not a significant factor in either blame allocation $\left(\chi^{2}=2.6302, p=0.621491 \mathrm{~ns}\right)$ or aggression rating for police (U=1667, $p=0.45326 n s$ ). This suggests that people do not just blame one party regardless based on political predispositions but are susceptible to the influence of language. Political affiliation is significant, though, in aggression ratings for protesters where participants who affiliate with Conservative (Republican) values are more likely to perceive protesters as more aggressive than participants who affiliate with Labour (Democrat) values ( $U=1389, p<.05)$. Interestingly, however, if we examine the effects of reciprocal versus regular transactive verbs on aggression rating for each group separately, we find no significant effect for Conservatives while Labour affiliates still perceive protesters as more aggressive in the regular transactive condition than the reciprocal condition $(U=1154, p<.001)$. This suggests a more entrenched view of protesters as deviant for Conservatives while those on the left of the political spectrum are likely to form more nuanced views on a context by context basis.

\section{Conclusion}

The experiment shows that seemingly minor lexico-grammatical differences of the kind typically singled out in critical discourse analyses can make a significant difference in social perceptions of the actors and actions involved in hard news events. The paper therefore goes some way to validating the general epistemology of CDA. However, we must be careful not to hold the findings of this one study up as evidence for the ideological functions of all lexico-grammatical constructions as they have been analysed elsewhere in CDA. Likewise, we must be careful not to attribute contextindependent functions and effects to particular forms. Given the basic tenets of CDA, such generalisations are unlikely to hold and are not particularly helpful. This paper has focussed solely on regular transactive versus reciprocal verbs in the specific context of reporting violence at political protests and the findings of the paper potentially extend only as far as this particular case study. Much more experimental work is therefore needed in CDA to show, through a range of independent case studies, that and how contrasting linguistic features function ideologically in different discursive contexts. We must also be cautious not to claim a simple causal link between discourse, cognition and social action. The relation between discourse and society is extremely complex, with all sorts of mediating factors - social, political and historical. The relation between discourse and cognition is 
Pre-proof version. Manuscript accepted for publication in Applied Linguistics.

similarly complex where the cognitive import of textual choices is subject to extra-textual factors like relative frequency, resonance and epistemic vigilance. However, this paper has demonstrated the utility of experimental methods in CDA by showing that specific linguistic differences observed in authentic discourse data do have consequences in cognition at least at the moment of interaction with the text. This serves to justify attention to these particular structures in future case studies of similar data. While certainly not claiming that all CDA should involve an experimental dimension, then, I do suggest that experimental methods can provide a fruitful form of triangulation for cognitive approaches CDA in particular where a useful way to proceed is from a discourse-analytical case study, which yields hypotheses concerning the cognitive effects of attested language usages, to an experimental study testing those predicted effects. This is further strengthened by a quantitative step in between to check that the pattern observed in a small data set represents a repeated pattern in a larger corpus.

\section{Acknowledgements}

With thanks to Sam Kirkham and Daniel Ezra Johnson for help with issues of design and statistical analysis. Any errors are my own.

\section{References}

Arpan, L.M., K. Baker, L. Youngwon, J. Taejin, L. Lorusso and J. Smith (2006). News coverage of social protestes and the effects of photographs on prior attitudes. Mass Communication \& Society 9 (1): 1-20.

Baker, P. and E. Levon (2015). Picking the right cherries? A comparison of corpus-based and qualitative analyses of news articles about masculinity. Discourse \& Communication 9 (2): 221236.

Behrend, T.S., D.J. Sharek, A.W. Meade and E.N. Weibe (2011). The viability of crowdsourcing for survey research. Behaviour Research Methods 43: 800-813.

Bergen, B.K. (2012). Louder than Words: The New of Science of How the Mind Makes Meaning. New York: Basic Books.

Boykoff, J. (2006). Framing dissent: Mass-media coverage of the Global Justice Movement. New Political Science 28 (2): 201-228.

Buhrmester M.D., T. Kwang and S.D. Gosling (2011). Amazon's Mechanical Turk: A new source of inexpensive, yet high-quality, data? Perspectives on Psychological Science 6 (1): 3-5.

Cameron, L. (2001). Working with Spoken Discourse. Oxford: Oxford University Press.

Casasanto, D. (2009). Embodiment of abstract concepts: good and bad in right- and left-handers. Journal of Experimental Psychology 138 (3): 351-367.

Charteris-Black, J. (2004). Corpus Approaches to Critical Metaphor Analysis. Basingstoke: Palgrave 
Pre-proof version. Manuscript accepted for publication in Applied Linguistics.

Cicourel, A. (1969). Method and Measurement in Sociology. New York: The Free Press.

Chilton, P. (2004). Analysing Political Discourse: Theory and Practice. London: Routledge.

Coffin, C. and K. O'Halloran (2006). The role of APPRAISAL and corpora in detecting covert evaluation. Functions of Language 13 (1): 77-110.

Coleman, R. (2010). Framing the pictures in our heads: Exploring the framing and agenda-setting effects of visual images. In P. D'Angelo and J.A. Kuypers (eds.), Doing News Framing Analysis. New York: Routledge. pp. 233-62.

Crump, J.C., J.V. McDonnel and T.M. Gureckis (2013). Evaluating Amazon's Mechanicial Turk as a tool for experimental behavioural research. PLOS ONE 8 e57410.

Denzin N.K. (1970). The Research Act: A Theoretical Introduction to Sociological Methods. Chicago, IL: Aldine.

Entman, R.M. (1993). Framing: Toward clarification of a fractured paradigm. Journal of Communication 4 (3): 51-58.

Fairclough, N. (1995). Critical Discourse Analysis: The Critical Study of Language. London: Longman.

Fausey, C.M. and T. Matlock (2011). Can grammar win elections? Political Psychology 32 (4): 563-74.

Fillmore, C. (1982). Frame semantics. In Linguistics Society of Korea (eds.), Linguistics in the Morning Calm. Seoul: Hanshin Publishing Co. pp. 111-137.

Germine, L., K.Nakayama, B.C. Duchine, C.F. Chabris, G. Chatterjee and J.B. Wilmer (2012). Is the Web as good as the lab? Comparable performance from Web and lab in cognitive/perceptual experiments. Pyschonomic Bulletin \& Review 19: 847-857.

Hackett, R and Y. Zhou (1994). Challenging a master narrative: Peace protest and opinion/editorial discourse in the US press during the Gulf War. Discourse \& Society 5 (4): 509-541.

Hall, S. (1973). A world at one with itself. In S. Cohen and J. Young (eds.), The Manufacture of News: Deviance, Social Problems and the Mass Media. London: Constable. pp. 147-156.

Hart, C. (2010). Critical Discourse Analysis and Cognitive Science: New Perspectives on Immigration Discourse. Basingstoke: Palgrave.

Hart, C. (2011a). Force-interactive patterns in immigration discourse: A Cognitive Linguistic approach to CDA. Discourse \& Society 22(3): 269-286.

Hart, C. (2011b). Legitimising assertions and the logico-rhetorical module: Evidence and epistemic vigilance in media discourse on immigration. Discourse Studies 13 (6): 751-769.

Hart, C. (2013a). Event-construal in press reports of violence in political protests: A Cognitive Linguistic Approach to CDA. Journal of Language and Politics 12(3): 400-423. 
Pre-proof version. Manuscript accepted for publication in Applied Linguistics.

Hart, C. (2013b). Constructing contexts through grammar: Cognitive models and conceptualisation in British Newspaper reports of political protests. In J. Flowerdew (ed.), Discourse and Contexts. London: Continuum, pp. 159-184.

Hart, C. (2014a). Discourse, Grammar and Ideology: Functional and Cognitive Perspectives. London: Bloomsbury.

Hart, C. (2014b). Construal operations in online press reports of political protests. In C. Hart and P. Cap (eds), Contemporary Critical Discourse Studies. London: Bloomsbury. pp. 167-188.

Hart, C. (2015). Viewpoint in linguistic discourse: Space and evaluation in news reports of political protests. Critical Discourse Studies 12 (3):238-260.

Hart, C. (in press a). Critical Cognitive Linguistics. In J. Flowerdew and J.E. Richardson (eds.), Handbook of Critical Discourse Analysis. London: Routledge.

Hart, C. (in press b). Cognitive analysis in Critical Discourse Studies: Connecting language and image. In B. Forchtner and R. Wodak (eds.), Handbook of Language and Politics. London: Routledge.

Henrich, J., S.J. Heine and A. Norenzayan (2010). The weirdest people in the world? Behavioural and Brain Sciences 33: 61-135.

Klein, R.A., K.A. Ratliff, M. Vianello, R.B. Jr Adams, S. Bahnik, M.J. Bernstein, et al., and J.A. Woodzicka (2014). Investigating variation in replicability. Social Psychology 45: 142-152.

Koller, V.K. (2004). Metaphor and Gender in Business Media Discourse: A Critical Cognitive Study. Basingstoke: Palgrave.

Koller, V. and P. Davidson (2008). Social exclusion as conceptual and grammatical metaphor: A crossgenre study of British policy-making. Discourse \& Society 19 (3): 307-331.

Koller, V. (2014). Cognitive linguistics and ideology. In J. Littlemore and J. Taylor (eds.), The Bloomsbury Companion to Cognitive Linguistics. London: Bloomsbury. pp. 234-252.

Koller, V. and G. Mautner (2004). Computer applications in critical discourse analysis. In C. Coffin, A. Hewings and K. O'Halloran (eds), Applying English Grammar: Functional and Corpus Approaches. London: Hodder and Stoughton. pp. 216-228.

Kress, G. and T. van Leeuwen (2006). Reading Images: The Grammar of Visual Design. London: Routledge.

Krzyzanowski, M. (2011). Political communication, institutional cultures, and linearities of organisation practice: A discourse-ethnographical approach to institutional change in the European Union. Critical Discourse Studies 8 (4): 281-296.

Langacker, R.W. (1987). Foundations of Cognitive Grammar, Volume I: Theoretical Prerequisites. Stanford, CA: Stanford University Press. 
Pre-proof version. Manuscript accepted for publication in Applied Linguistics.

Langacker, R.W. (1991). Foundations of Cognitive Grammar, Volume II: Descriptive Application. Stanford, CA: Stanford University Press.

Langacker, R.W. (1999). Grammar and Conceptualization. Berlin: Walter de Gruyter.

Langacker, R.W. (2008). Cognitive Grammar: A Basic Introduction. Oxford: Oxford University Press.

Macleod, D. And J. Hertog (1992). The manufacture of "public opinion" by reporters: Informal cues for publication perceptions of protest groups. Discourse \& Society 3 (3): 259-275

MacWhinney, B. (2008). How mental models encode embodied linguistic perspectives. In R. Klatzky, B. MacWhinney and M. Behrmann (eds.), Embodiment, Ego-Space and Action. Mahwah: Laurence Erlbaum. pp. 369-410.

Maillat, D. and S. Oswald (2011). Constraining context: A pragmatic account of cognitive manipulation. In C. Hart (eds.), Critical discourse studies in context and cognition. Amsterdam: John Benjamins. pp. 65-80.

Mason, W. and S. Suri (2012). Conducting behavioural research on Amazon's Mechanical Turk. Behavioural Research Methods 44: 1-23.

Murdock, G. (1973). Political deviance: The press presentation of a militant mass demonstration. In S. Cohen and J. Young (eds.), The Manufacture of News: Deviance, Social Problems and the Mass Media. London: Constable. pp. 206-225.

McManus, C. (2003). Right Hand, Left Hand. Pheonix

Nelson, T.E., Z.M. Oxley and R.A. Clawson (1997). Toward a psychology of framing effects. Political Behavior 19 (3): 221-46.

Newhagen, J.E. and B. Reeves (1992). This evening's bad news: Effects of compelling negative television news images on memory. Journal of Communication 42 (2): 25-41.

O'Halloran, K. (2003). Critical Discourse Analysis and Language Cognition. Edinburgh: Edinburgh University Press.

O'Halloran, K. (2005). Causal cognition and socio-cognition in critical discourse analysis: A reply to Rick ledema. Linguistics and Education 16: 338-348.

Ofcom (2014). News Consumption in the UK: 2014 Report. http://stakeholders.ofcom.org.uk/binaries/research/tvresearch/news/2014/News Report 2014.pdf

Oswald, S. and C. Hart (2014). Trust based on bias: Cognitive constraints on source-related fallacies. In D. Mohammed and M. Lewiński (eds), Virtues of Argumentation. Proceedings of the 10th International Conference of the Ontario Society for the Study of Argumentation (OSSA). Windsor, ON: OSSA, pp. 1-13.

Paolacci, G., J. Chandler and P.G. Ipeirotis (2010). Running experiments on Amazon Mechanical Turk. Judgement and Decision Making 5: 411-419. 
Pre-proof version. Manuscript accepted for publication in Applied Linguistics.

Perniss, P., R. Thompson and G. Vigliocco (2010). Iconicity as a general property of language: Evidence from spoken and signed languages. Frontiers in Psychology 1: 227.

Powell, T.E., H.G. Boomgaarden, K. De Swert and C.H. de Vreese (2015). A clearer picture: The contribution of visual and text to framing effects. Journal of Communication. DOI: $10.1111 /$ jcom.12184

Reisigl, M. and R. Wodak (2001). Discourse and Discrimination: Rhetorics of Racism and AntiSemitism. London: Routledge.

Ruppenhofer, J., M. Ellsworth, M.R.L. Petruck, C.R. Johnson and J. Scheffczyk (2010). FrameNet II: Extended Theory and Practice. Available at: https://framenet2.icsi.berkeley.edu/docs/r1.5/book.pdf

Schuck, R.T. and C.H. de Vreese (2006). Between risk and opportunity: News framing and its effects on public support for EU enlargement. European Journal of Communication 21: 5-31.

Talmy, L. (2000). Toward a Cognitive Semantics, vol. I: Concept Structuring Systems. Chicago: University of Chicago Press.

Thibodeau P.H and L. Boroditsky (2011). Metaphors we think with: The role of metaphor in reasoning. PLOS ONE 6(2): e16782. doi:10.1371/journal.pone.0016782

Thibodeau P.H and L. Boroditsky (2013). Natural language metaphors covertly influence reasoning. PLOS ONE 8(1): e52961. doi:10.1371/journal.pone.0052961

Van Dijk, T.A. (1993). Principles of critical discourse analysis. Discourse \& Society 4 (2): 243-89.

Van Dijk, T.A. (2009). Critical discourse studies: A sociocognitive approach. In R. Wodak and M. Meyer (eds.), Methods of Critical Discourse Analysis, $2^{\text {nd }}$ edn. London: Sage. pp. 62-86.

Van Dijk, T.A. (2014). Discourse-cognition-society: Current state and prospects of the socio-cognitive approach to discourse. In C. HART and P. Cap (eds.), Contemporary Critical Discourse Studies. London: Bloomsbury. pp. 121-146.

Widdowson, H.G. (2004). Text, Context, Pretext: Critical Issues in Discourse Analysis. Oxford: Blackwell.

Wodak, R. (2006). Mediation between discourse and society: Assessing cognitive approaches in CDA. Discourse Studies 8 (1): 179-90.

Wodak, R. and M. Krzyzanowski (eds.) (2008). Qualitative Discourse Analysis in the Social Sciences. Basingstoke: Palgrave.

Woods, A.T., C. Velasco, C.A. Levitan, X. Wan and C. Spence (2015). Conducting perception research over the internet: A tutorial review. Peer J 3 e1058. 